\begin{tabular}{|c|l|}
\hline Title & Importance of water content in formation of porous anodic niobium oxide films in hot phosphate glycerol electrolyte \\
\hline Author(s) & Habazaki, H.; Oikawa, Y.; Fushimi, K.; A oki, Y.; Shimizu, K.; Skeldon, P.; Thompson, G.E. \\
\hline Citation & $\begin{array}{l}\text { Electrochimica A cta, 54/3), 946-951 } \\
\text { https://doi.org/10.1016/.electacta.2008.08.031 }\end{array}$ \\
\hline Issue Date & 2009-01-01 \\
\hline Doc URL & http://hdl.handle.net/2115/35512 \\
\hline Type & article(author version) \\
\hline File Information & EA_54_2009_2.pdf \\
\hline
\end{tabular}

Instructions for use 


\section{Importance of Water Content in Formation of Porous Anodic Niobium Oxide Films in}

\section{Hot Phosphate-Glycerol Electrolyte}

H. Habazaki ${ }^{\mathrm{a}, 1, *}$, Y. Oikawa ${ }^{\mathrm{a}}$, K. Fushimi ${ }^{\mathrm{a}}$, Y. Aoki ${ }^{\mathrm{a}}$, K. Shimizu ${ }^{\mathrm{b}}$, P. Skeldon ${ }^{\mathrm{c}}$ and G.E.

Thompson $^{\mathrm{c}}$

Graduate School of Engineering, Hokkaido University, Sapporo 060-8628, Japan

*University Chemical Laboratory, Keio University, 4-1-1 Hiyoshi, Yokohama 223-8521, Japan

**Corrosion and Protection Centre, School of Materials, The University of Manchester, P.O.

Box 88, Manchester M60 1QD, UK

${ }^{1}$ ISE member

*Corresponding author: Tel. +81-11-706-6575, e-mail habazaki@eng.hokudai.ac.jp 
Abstract

Niobium has been anodized at a constant current density to $10 \mathrm{~V}$ with a current decay in 0.8 mol dm${ }^{-3} \mathrm{~K}_{2} \mathrm{HPO}_{4}$-glycerol electrolyte containing 0.08 to 0.65 mass $\%$ water at $433 \mathrm{~K}$ to develop porous anodic oxide films. The film growth rate is markedly increased when the water content is reduced to 0.08 mass $\%$; a $28 \mu \mathrm{m}$-thick porous film is developed in this electrolyte by anodizing for $3.6 \mathrm{ks}$, while the thickness is 4.6 and $2.6 \mu \mathrm{m}$ in the electrolytes containing 0.16 and 0.65 mass $\%$ water respectively. For all the electrolytes, the film thickness changes approximately linearly with the charge passed during anodizing, indicating that chemical dissolution of the developing oxide is negligible. SIMS depth profiling analysis was carried for anodic films formed in electrolyte containing $\sim 0.4$ mass $\%$ water with and without enrichment of $\mathrm{H}_{2}{ }^{18} \mathrm{O}$. Findings disclose that water in the electrolyte is a predominant source of oxygen in the anodic oxide films. The anodic films formed in the electrolyte containing 0.65 mass \% water are practically free from phosphorus species. Reduction in water content increased the incorporation of phosphorus species.

Keywords: Anodic oxide, niobium, porous oxide, glycerol electrolyte 


\section{Introduction}

In addition to the well-known porous anodic alumina films with cylindrical pores arranged normal to the metal/film interface, it is now possible to form self-organized porous anodic oxides on a range of valve metals, including niobium, tantalum, titanium, tungsten and zirconium, in fluoride-containing electrolytes \{Beranek, 2003 \#1341; Sieber, 2005 \#1343; Tsuchiya, 2005 \#1344; Tsuchiya, 2005 \#1345; Tsuchiya, 2004 \#1346; Wei, 2008 \#1348\}. The porous anodic oxides have attracted much attention concerning their formation mechanisms and potential widespread applications.

Recently, it has been found that porous anodic oxides can also be formed on aluminium, niobium, tantalum and Ti-Si alloys in hot glycerol electrolyte containing phosphate $\{\mathrm{Lu}, 2002$ \#580; Lu, 2005 \#1182; Habazaki, 2007 \#1367\}, although initially the films formed in this electrolyte were considered to be of a barrier-type \{Melody, $1998 \# 1043$. The film morphologies closely resemble that of the well-known porous anodic alumina produced in aqueous acid electrolytes; an outer layer, containing nano-scale, almost cylindrical, parallel-sided pores, is developed above a thin barrier layer that separates the porous layer and the metal substrate $\left\{\mathrm{O}^{\prime}\right.$ Sullivan, $\left.1970 \# 1248\right\}$. The anodic films formed in the glycerol electrolyte consist of the oxides of the respective valve metals, with negligible incorporation of phosphorus species, although the oxides developed in aqueous electrolytes 
are usually contaminated with species derived from electrolyte anions \{Wood, $1996 \# 41$ \}. Although morphological and compositional characterization of the anodic oxide films formed in phosphate-glycerol electrolyte has been carried out, the mechanism of film formation, particularly, the origin of oxide ions, has not yet been clarified.

In the present study, porous anodic oxide films have been formed in phosphate-glycerol electrolytes containing $0.08-0.65$ mass $\%$ water at $433 \mathrm{~K}$. The influence of water concentration on the growth behaviour of porous oxide has been examined. The films developed have been characterized by field emission scanning electron microscopy and glow discharge optical emission spectroscopy (GDOES). In order to elucidate the origin of the oxide ions in the anodic films, SIMS depth profiling analysis has been carried out for films developed in the electrolyte with $\sim 0.4$ mass $\%$ water with and without enrichment of $\mathrm{H}_{2}{ }^{18} \mathrm{O}$.

\section{Experimental}

The specimens used for anodizing were cut from $99.9 \%$ niobium sheet, of $0.2 \mathrm{~mm}$ thickness; individual specimens were ultrasonically degreased in acetone. The electrolytes employed for anodizing were $0.8 \mathrm{~mol} \mathrm{dm}^{-3}$ dibasic potassium phosphate in glycerol containing $0.08,0.16$ or 0.65 mass $\%$ water at $433 \mathrm{~K}$. The water concentration in the electrolytes was measured by Karl Fischer titration using a Hiranuma Sangyo, AQV-7S instrument. The specimens, masked with silicone resin to define the exposed surface area, 
were anodized at a constant current density of $250 \mathrm{~A} \mathrm{~m}^{-2}$ to $10 \mathrm{~V}$, followed by holding at $10 \mathrm{~V}$ for a total anodizing time of $3.6 \mathrm{ks}$. The anodizing procedure used a two-electrode cell with a platinum counter electrode.

The anodized specimens were re-anodized at a constant current density of $5 \mathrm{~A} \mathrm{~m}^{-2}$ in $0.5 \mathrm{~mol} \mathrm{dm}^{-3} \mathrm{H}_{3} \mathrm{BO}_{3}-0.05 \mathrm{~mol} \mathrm{dm}^{-3} \mathrm{Na}_{2} \mathrm{~B}_{4} \mathrm{O}_{7}$ aqueous electrolyte at $293 \mathrm{~K}$, and the initial voltage surges were measured to estimate the thickness of the barrier layer between the porous layer and the underlying metal substrate.

Surfaces and fracture sections of the anodized specimens were observed using a JEOL JSM6500 scanning electron microscope operated at $10 \mathrm{kV}$. Depth profiles of the anodized specimens were obtained by GDOES, using a Jobin-Yvon 5000 RF instrument, in an argon atmosphere of $650 \mathrm{~Pa}$ with application of RF of $13.56 \mathrm{MHz}$ and power of $30 \mathrm{~W}$. Light emissions of characteristic wavelengths were monitored throughout the analysis with a sampling time of $0.1 \mathrm{~s}$ to obtain depth profiles. The wavelengths of the spectral lines used were $416.477,178.287,130.217,165.701$ and $121.567 \mathrm{~nm}$ for niobium, phosphorus, oxygen, carbon and hydrogen, respectively. The signals were detected from a circular area of approximately $4 \mathrm{~mm}$ diameter.

Further, secondary ion mass spectroscopy (SIMS) depth profiles were obtained using a PHI, ADEPT1010 instrument. A $5 \mathrm{keV} \mathrm{Cs}^{+}$primary ion beam was used for sputtering. The specimens for SIMS depth profiles were prepared by anodizing niobium in a manner similar 
to that described previously, but the anodizing time was only 600 s. Prior to anodizing, either $95 \% \mathrm{H}_{2}{ }^{18} \mathrm{O}$ or distilled water was added to $0.8 \mathrm{~mol} \mathrm{dm}{ }^{-3}$ dibasic potassium phosphate in glycerol containing approximately 0.08 mass $\%$ water. The resulting water concentration, including $\mathrm{H}_{2}{ }^{18} \mathrm{O}$, was $\sim 0.4$ mass $\%$.

\section{Experimental Results}

Figure 1 shows current transients during anodizing of niobium at $10 \mathrm{~V}$ in the $\mathrm{K}_{2} \mathrm{HPO}_{4}$-glycerol electrolytes containing $0.08,0.16$ and 0.65 mass $\%$ water at $433 \mathrm{~K}$. A constant current density of $250 \mathrm{~A} \mathrm{~m}^{-2}$ was applied initially before reaching $10 \mathrm{~V}$. In the electrolytes containing 0.65 mass $\%$ water, the voltage reaches $10 \mathrm{~V}$ almost immediately (Fig. 1(b)), and the current density subsequently decreases steeply to $10 \mathrm{~A} \mathrm{~m}^{-2}$ during the initial period of holding at constant voltage. After approximately $1.0 \mathrm{ks}$, the current density then gradually increased up to $19 \mathrm{~A} \mathrm{~m}^{-2}$. The current transient in the electrolyte containing 0.16 mass $\%$ water is similar to that in the electrolyte containing 0.65 mass $\%$ water, but the current density is higher in the electrolyte containing 0.16 mass $\%$ up to approximately $3.0 \mathrm{ks}$. The current maximum appears at about $1.3 \mathrm{ks}$ in the electrolyte containing 0.16 mass $\%$ water, followed by a gradual decrease in the current density. A markedly increased current density is observed when niobium is anodized in the electrolyte containing only 0.08 mass $\%$ water. In this electrolyte, the voltage does not rise immediately to $10 \mathrm{~V}$, maintaining $\sim 6 \mathrm{~V}$ for $150 \mathrm{~s}$. 
The voltage then increased rapidly to $10 \mathrm{~V}$, and the current density decreased steeply, but only to $\sim 180 \mathrm{~A} \mathrm{~m}^{-2}$. The current density further decreased gradually with anodizing time, but the current density after anodizing for $3.6 \mathrm{ks}$ approaches $125 \mathrm{~A} \mathrm{~m}^{-2}$, approximately one order of magnitude higher than that in the electrolytes with increased water contents.

In all the electrolytes with different water contents, porous anodic oxide films were developed as shown in scanning electron micrographs of surfaces of the anodized specimens (Fig. 2). The anodic oxide films developed in the electrolyte containing 0.08 mass $\%$ water consisted of two layers; an outer layer is formed at an initial formation voltage of $\sim 6 \mathrm{~V}$ and the inner layer after reaching $10 \mathrm{~V}$. The surface of the outer layer developed during anodizing at an initial constant current density (formation voltage of $\sim 6 \mathrm{~V}$ ) is shown in Fig. 2((a). The highly cracked outer layer was detached readily and, in the detached region, the porous inner layer with pore size as small as $7-12 \mathrm{~nm}$ is obvious (Fig. 2(b)). In the electrolytes with increased water contents, a single-layered anodic oxide film is developed since the voltage rapidly reached $10 \mathrm{~V}$ after the commencement of anodizing. The films are porous, with a pore size of $10-20 \mathrm{~nm}$, which is slightly larger than that in the electrolyte containing 0.08 mass $\%$ water. The pore population density is approximately $1.1 \times 10^{15} \mathrm{~m}^{-2}$, irrespective of the water content of the electrolytes used.

Considering the current densities during anodizing in the electrolytes with differing water contents, the thicknesses of the anodic oxide films are greatly dependent upon the water 
content. A porous anodic oxide film of $28 \mu \mathrm{m}$ thickness is developed in the electrolyte containing 0.08 mass $\%$ water (Fig. 3(a)), while the thicknesses are only $2.6 \mu \mathrm{m}$ (Fig. (3(c)) and $4.6 \mu \mathrm{m}$ (Fig. 3(b)) for the films developed in the electrolytes containing 0.65 and 0.16 mass $\%$ water, respectively. The anodic oxide film formed in the electrolyte containing 0.08 mass $\%$ water clearly consists of an outer layer, indicated by arrows in Fig. 3(a), of only 6\% of the total film thickness and an inner layer of uniform thickness. A high magnification image of the inner layer, shown in the inset of Fig. 3(a), discloses the development of approximately cylindrical pores that pass almost perpendicularly to the metal/film interface, resembling porous anodic alumina films formed in aqueous acid electrolytes. A similar pore morphology was disclosed in the outer layer.

The anodic oxide films formed in the electrolytes containing 0.16 and 0.65 mass $\%$ water (Fig. 3(b) and (c)) are composed of a single layer, since the voltage increased almost immediately to $10 \mathrm{~V}$ at the commencement of anodizing. Cylindrical pores are again present throughout almost the whole of the film thickness, although a thin barrier layer is probably present immediately above the metal substrate. The pore sizes observed from cross-sectional observations are in agreement with those obtained from surface observations. The smaller pore size of the anodic oxide film formed in the electrolyte with 0.08 mass $\%$ water may be associated with a thinner barrier layer formed in this electrolyte compared with that formed in the electrolytes with higher water contents, as discussed later. Another possibility is increased 
chemical dissolution rate of the pore wall in the electrolyte with higher water content; the increased water content enhances the rate of pore widening. However, anodizing time dependence of the pore size revealed that pore widening during anodizing was negligible even in the electrolyte containing 0.65 mass $\%$ water.

The thicknesses of the anodic films developed in the electrolytes containing different water concentrations have a linear correlation with the charge passed during anodizing (Fig. 4). A slope of $5.87 \times 10^{-11} \mathrm{~m}^{3} \mathrm{C}^{-1}$ is calculated for growth of barrier-type anodic niobia of density $4.7 \mathrm{~g} \mathrm{~cm}^{-3}$ \{Pringle, $1980 \# 10$ \} at an efficiency of $100 \%$, which is $10 \%$ higher than the measured value of $5.31 \times 10^{-11} \mathrm{~m}^{3} \mathrm{C}^{-1}$. The thicknesses of the outer and inner layers of the anodic oxide film formed during constant current and constant voltage anodizing respectively, in the electrolyte containing 0.08 mass $\%$ water also follow this linear correlation. The thinning of anodic films by chemical dissolution during anodizing appears to be negligible compared with the rate of film growth.

Qualitative elemental depth profiles obtained by GDOES (Fig. 5) reveal that the anodic films are mainly composed of niobium oxide. Hydrogen species are present, particularly in the outer part of the film. However, since the intensity of oxygen is relatively constant throughout the film thickness, the concentration of hydroxide and/or hydrated oxide should be rather low. The intensity of phosphorus in the anodic films formed in the electrolyte containing 0.65 mass $\%$ water is at the background level; hence, the incorporation of 
phosphorus species into these anodic films is negligible (Fig. 5(c)). The relatively high background level of the phosphorus signal may be due to overlapping with an emission line from argon (178.258 nm) \{Payling, $1997 \# 637$. A slight incorporation of phosphorus species occurs in the anodic film formed in the electrolyte with 0.16 mass $\%$ water (Fig. 5(b)). The incorporation is further enhanced when the electrolyte with 0.08 mass $\%$ water is used (Fig. 5(a)). An increased incorporation of carbon species, derived from glycerol, appears to occur in the electrolyte with 0.08 mass \% water. Since the intensity of hydrogen in the anodic film is not increased for the specimen formed in the electrolyte with 0.08 mass $\%$ water, carbon species in the anodic film may no longer be present as glycerol molecules, as in alumina films formed in aqueous electrolytes containing organic acids \{Yamamoto, $1983 \# 1349$ \}.

Depth profiling analysis was further conducted by SIMS to examine the origin of oxide ions in the anodic films formed in the present organic electrolyte. For SIMS analysis, the anodic films were developed in the $\mathrm{K}_{2} \mathrm{HPO}_{4}$-glycerol electrolyte with $\sim 0.4$ mass $\%$ water of natural $\mathrm{H}_{2}{ }^{18} \mathrm{O}$ abundance and of enriched $\mathrm{H}_{2}{ }^{18} \mathrm{O}$ abundance. It is clear from Fig. 6 that the intensity of ${ }^{18} \mathrm{O}^{-}$is markedly increased in the anodic film formed in the electrolyte with $\mathrm{H}_{2}{ }^{18} \mathrm{O}$-enriched water. The intensity ratio of ${ }^{16} \mathrm{O}^{-}$and ${ }^{18} \mathrm{O}^{-}$in the anodic film formed in the electrolyte with conventional water is in agreement with the ratio of natural abundance of ${ }^{16} \mathrm{O}$ and ${ }^{18} \mathrm{O}$.

The presence of phosphorus species in the anodic films is evident in the SIMS depth 
profiles. However, the GDOES depth profile of the anodic film formed in the electrolyte containing 0.65 mass \% water (Fig. 5(c)) could not detect the presence of phosphorus species in the anodic film, reflecting a reduced sensitivity compared with SIMS.

\section{Discussion}

SIMS depth profiles disclose that the oxygen species in the anodic films formed in hot $\mathrm{K}_{2} \mathrm{HPO}_{4}$-glycerol electrolyte are derived predominantly from water in the electrolyte, not from glycerol itself, at least when the water content is approximately 0.4 mass $\%$. In the electrolyte containing 0.08 mass $\%$ water, a $28 \mu \mathrm{m}$-thick anodic film was developed after anodizing for $3.6 \mathrm{ks}$. Assuming a porosity of $10 \%$, consistent with the measured size and distribution of pores, the density of anodic niobium oxide is estimated to be $4.3 \mathrm{~g} \mathrm{~cm}^{-3}$ using the density of barrier type anodic niobium oxide $\left(4.7 \mathrm{~g} \mathrm{~cm}^{-3}\right)$ SSchrijner, $\left.1964 \# 1350\right\}$. Then, the number of $\mathrm{O}^{2-}$ ions in the anodic film of area $4 \mathrm{~cm}^{2}$ is $4.8 \times 10^{20}$ ions. The number of water molecules in the electrolyte $(300 \mathrm{~g})$ is $8 \times 10^{21}$ molecules, which is only one order of magnitude larger than the oxygen content of the film. The relatively small difference suggests that in the electrolyte containing 0.08 mass $\%$ water, supply of water to the niobium electrode may be a limiting factor in film growth processes.

In order to examine whether the thickness of the barrier layer between the porous layer and substrate changes with the water content in electrolyte, the anodized specimens were re-anodized at a constant current density of $5 \mathrm{~A} \mathrm{~m}^{-2}$ in $0.5 \mathrm{~mol} \mathrm{dm}{ }^{-3} \mathrm{H}_{3} \mathrm{BO}_{3}-0.05 \mathrm{~mol}$ 
$\mathrm{dm}^{-3} \mathrm{Na}_{2} \mathrm{~B}_{4} \mathrm{O}_{7}$ aqueous electrolyte to measure the voltage surge immediately after applying the constant current. The results are summarized in Table 1, together with the final current densities after anodizing at $10 \mathrm{~V}$ in the glycerol electrolyte at $433 \mathrm{~K}$. The voltage surge for the specimen anodized in the electrolyte containing 0.08 mass $\%$, of $8.1 \mathrm{~V}$, is only $60 \%$ of that of the specimens anodized in the electrolytes with increased water contents. Similar voltage surges for the specimens anodized in the electrolytes with 0.16 and 0.65 mass $\%$ water reflect the similar final current densities during anodizing in the glycerol electrolyte. The higher current density in the glycerol electrolyte containing only 0.08 mass $\%$ water is, therefore, associated with a higher field strength in the relatively thin barrier layer of the film. It is known that incorporation of electrolyte anions is enhanced at higher electric field \{ $\mathrm{Lu}, 2004$ $\# 1011\}$. Thus, the increased incorporation of phosphorus species in the anodic film formed in the electrolyte containing 0.08 mass $\%$ water can be explained in terms of the electric field across the barrier layer of the anodic film.

The importance of water content in growth of anodic oxide films has been pointed out for the growth of porous titanium oxide nanotube layers on titanium in fluoride-containing organic electrolytes at $298 \mathrm{~K}$ \{Paulose, $2006 \# 1333$ \}; the use of organic electrolytes, including dimethyl sulphoxide, formamide, ethylene glychol and $\mathrm{N}$-methylformamide, with less than $5 \%$ water is a key to generate very long nanotube arrays. However, there is an optimal water content to obtain the highest growth rate, which is $2 \%$ water \{Prakasam, 2007 
$\# 1312\}$. In contrast, the rate of film growth increases with reducing water content in the present work. The difference in behaviours may arise from the presence or absence of fluoride ions in the electrolyte. In electrolytes without fluoride ions, as in the present case, film formation may become predominant, relative to field-assisted ejection of cations at the film/electrolyte interface of pore base, when a sufficient amount of water is present in the electrolyte. The reduction of water content appears to be essential to promote the field-assisted ejection of niobium ions into the electrolyte, and hence to develop a porous layer. In the fluoride-containing electrolytes, the field-assisted ejection occurs to form porous oxide even in aqueous electrolytes. A dynamic balance between the rate of water supply to the pore base to form oxide and chemical dissolution of the oxide film developed determines the optimal water content to achieve highest growth rate of titanium oxide nanotube arrays in fluoride-containing organic electrolytes \{Prakasam, $2007 \# 1312$ \}.

\section{Conclusions}

1. Porous anodic niobium oxide films develop at $10 \mathrm{~V}$ in the $\mathrm{K}_{2} \mathrm{HPO}_{4}$-glycerol electrolytes containing $0.08-0.65$ mass $\%$ water at $433 \mathrm{~K}$. The growth rate increases with reduction of water content; a $28 \mu$ m-thick film is formed by anodizing in the electrolyte with 0.08 mass $\%$ water for $3.6 \mathrm{ks}$.

2. Water in the electrolyte is a predominant source of $\mathrm{O}^{2-}$ ions in the anodic films. 
3. The barrier layer, sandwiched between the porous layer and the metal substrate, is relatively thin in the electrolyte with 0.08 mass $\%$ water. The resultant increased field strength appears to enhance the growth rate of the film.

4. A higher concentration of phosphorus species, incorporated in the film formed in electrolyte with reduced water content, is probably associated with the increased field strength.

Acknowledgments

The present work was supported by a Grant-in-Aid for Exploratory Research, No. 19656184 from the Japan Society for the Promotion of Science, and also by the Global COE Program (Project No. B01: Catalysis as the Basis for Innovation in Materials Science) from the Ministry of Education, Culture, Sports, Science and Technology, Japan.

\section{References}


Figure captions

Fig. 1 (a) Current- and voltage-time responses during anodizing of niobium at $10 \mathrm{~V}$ for 3.6 ks in $0.8 \mathrm{~mol} \mathrm{dm}^{-3} \mathrm{~K}_{2} \mathrm{HPO}_{4}$-glycerol electrolytes with $0.08,0.16$ and 0.65 mass $\%$ water at 433

$\mathrm{K}$. A constant current density of $250 \mathrm{~A} \mathrm{~m}^{-2}$ was applied initially until the voltage reached $10 \mathrm{~V}$. (b) the same responses but during initial anodizing for $300 \mathrm{~s}$.

Fig. 2 Scanning electron micrographs of the surfaces of niobium specimens anodized at 250 $\mathrm{A} \mathrm{m}^{-2}$ to $10 \mathrm{~V}$ with current decay for $3.6 \mathrm{ks}$ in $0.8 \mathrm{~mol} \mathrm{dm}^{-3} \mathrm{~K}_{2} \mathrm{HPO}_{4}$-glycerol electrolytes with (a) 0.08 , (c) 0.16 and (d) 0.65 mass $\%$ water at $433 \mathrm{~K}$. The surface of the inner oxide layer after removal of the outer oxide layer formed in the electrolyte with 0.08 mass $\%$ water is shown in (b).

Fig. 3 Scanning electron micrographs of fracture sections of niobium specimens anodized at $250 \mathrm{~A} \mathrm{~m}^{-2}$ to $10 \mathrm{~V}$ with current decay for $3.6 \mathrm{ks}$ in $0.8 \mathrm{~mol} \mathrm{dm}^{-3} \mathrm{~K}_{2} \mathrm{HPO}_{4}$-glycerol electrolytes with (a) 0.08 , (c) 0.16 and (d) 0.65 mass $\%$ water at $433 \mathrm{~K}$. The insets are high magnification images of the respective anodic films.

Fig. 4 Correlation between the thickness of the anodic oxide films formed and the electric 
charge passed during anodizing at $250 \mathrm{~A} \mathrm{~m}^{-2}$ to $10 \mathrm{~V}$ with current decay for $3.6 \mathrm{ks}$ in $0.8 \mathrm{~mol}$ $\mathrm{dm}^{-3} \mathrm{~K}_{2} \mathrm{HPO}_{4}$-glycerol electrolytes with three different water contents at $433 \mathrm{~K}$. The correlation for the anodic film formed during initial constant current anodizing and that during the subsequent constant voltage anodizing in the electrolyte containing 0.08 mass $\%$ water are also plotted.

Fig. 5 GDOES elemental depth profiles of niobium specimens anodized at $250 \mathrm{~A} \mathrm{~m}^{-2}$ to $10 \mathrm{~V}$ with current decay for $3.6 \mathrm{ks}$ in $0.8 \mathrm{~mol} \mathrm{dm}^{-3} \mathrm{~K}_{2} \mathrm{HPO}_{4}$-glycerol electrolytes with (a) 0.08 , (c) 0.16 and (d) 0.65 mass $\%$ water at $433 \mathrm{~K}$.

Fig. 6 SIMS depth profiles of the niobium specimens anodized at $250 \mathrm{~A} \mathrm{~m}^{-2}$ to $10 \mathrm{~V}$ with current decay for $600 \mathrm{~s}$ in $0.8 \mathrm{~mol} \mathrm{dm}{ }^{-3} \mathrm{~K}_{2} \mathrm{HPO}_{4}$-glycerol electrolytes (a) with $\mathrm{H}_{2}{ }^{18} \mathrm{O}$ enrichment and (b) without $\mathrm{H}_{2}{ }^{18} \mathrm{O}$ enrichment at $433 \mathrm{~K}$. 
(a)

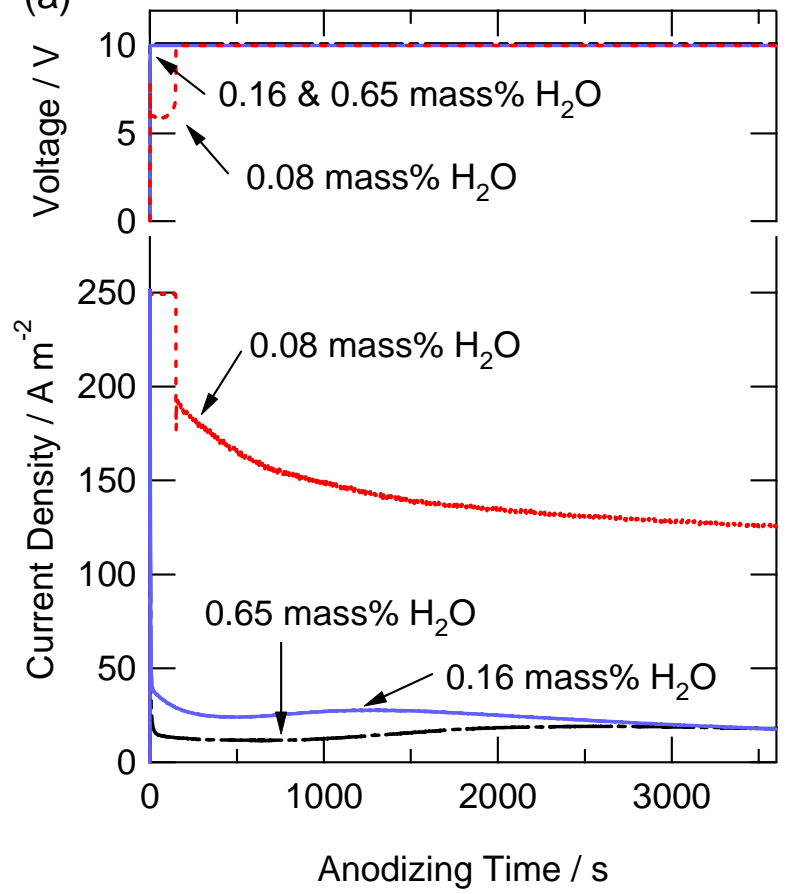

(b)

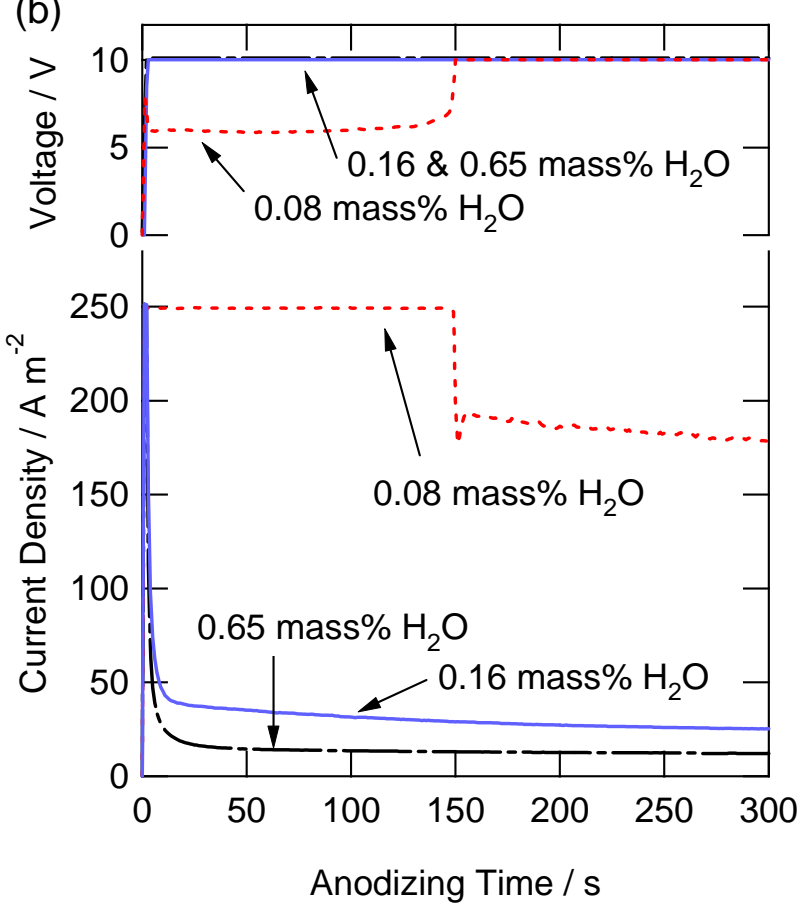

Fig. 1 (a) Current- and voltage-time responses during anodizing of niobium at $10 \mathrm{~V}$ for 3.6 ks in $0.8 \mathrm{~mol} \mathrm{dm}^{-3} \mathrm{~K}_{2} \mathrm{HPO}_{4}$-glycerol electrolytes with $0.08,0.16$ and 0.65 mass\% water at 433 $\mathrm{K}$. A constant current density of $250 \mathrm{~A} \mathrm{~m}^{-2}$ was applied initially until the voltage reached $10 \mathrm{~V}$. (b) the same responses but during initial anodizing for $300 \mathrm{~s}$. 

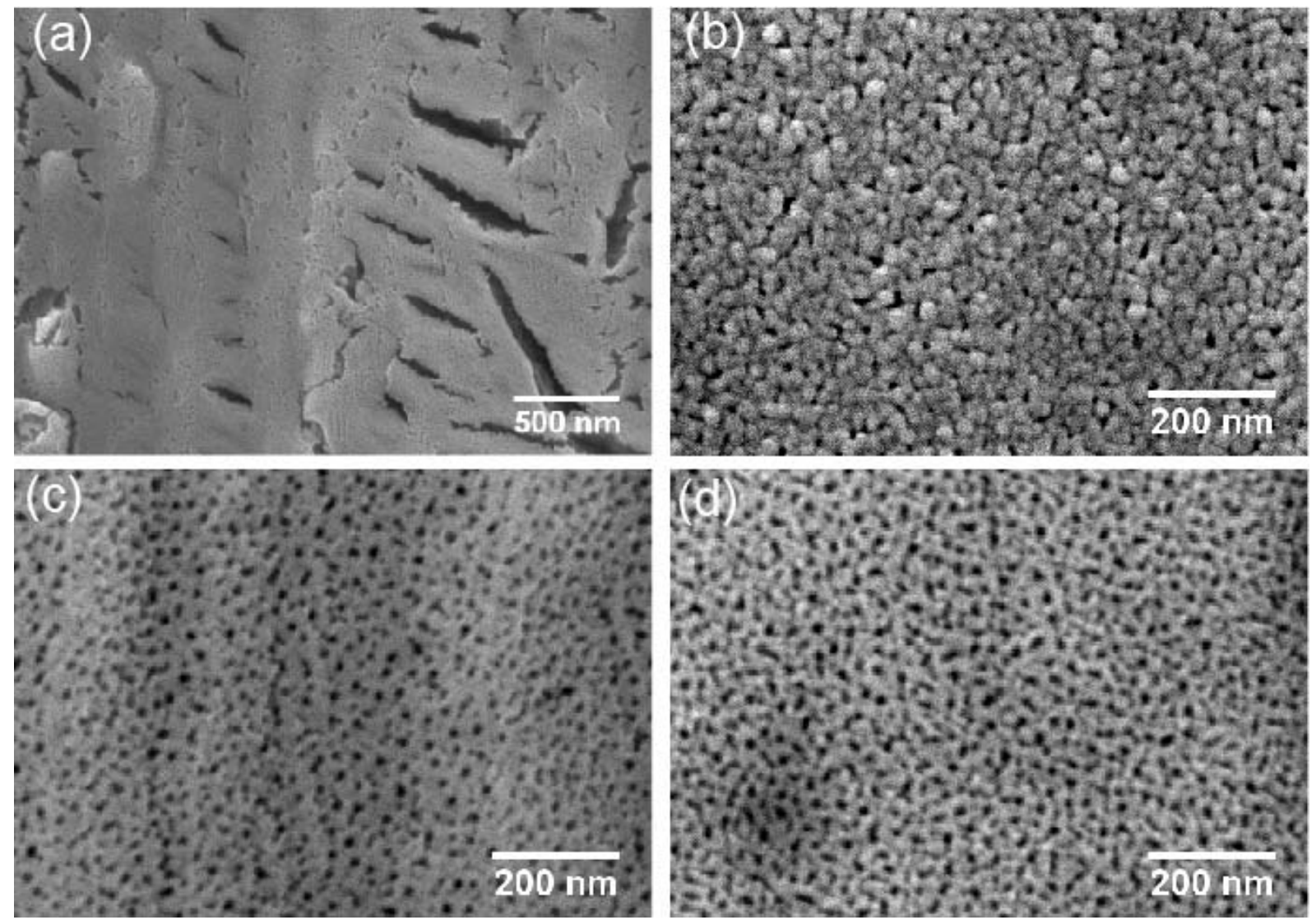

Fig. 2 Scanning electron micrographs of the surfaces of niobium specimens anodized at 250 $\mathrm{A} \mathrm{m}^{-2}$ to $10 \mathrm{~V}$ with current decay for $3.6 \mathrm{ks}$ in $0.8 \mathrm{~mol} \mathrm{dm}{ }^{-3} \mathrm{~K}_{2} \mathrm{HPO}_{4}$-glycerol electrolytes with (a) 0.08 , (c) 0.16 and (d) 0.65 mass $\%$ water at $433 \mathrm{~K}$. The surface of the inner oxide layer after removal of the outer oxide layer formed in the electrolyte with 0.08 mass\% water is shown in (b). 

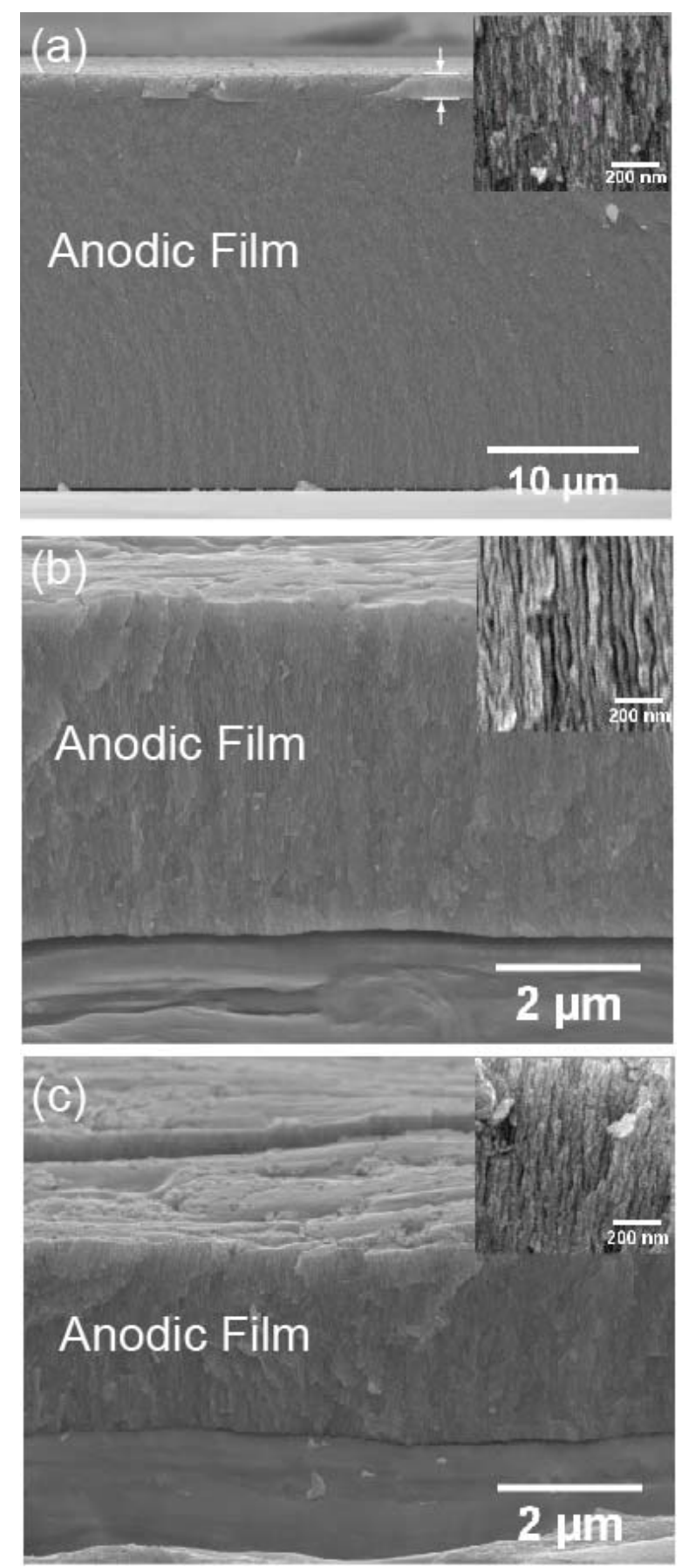

Fig. 3 Scanning electron micrographs of fracture sections of niobium specimens anodized at $250 \mathrm{~A} \mathrm{~m}^{-2}$ to $10 \mathrm{~V}$ with current decay for $3.6 \mathrm{ks}$ in $0.8 \mathrm{~mol} \mathrm{dm}^{-3} \mathrm{~K}_{2} \mathrm{HPO}_{4}$-glycerol electrolytes with (a) 0.08 , (c) 0.16 and (d) 0.65 mass\% water at $433 \mathrm{~K}$. The insets are high magnification images of the respective anodic films. 


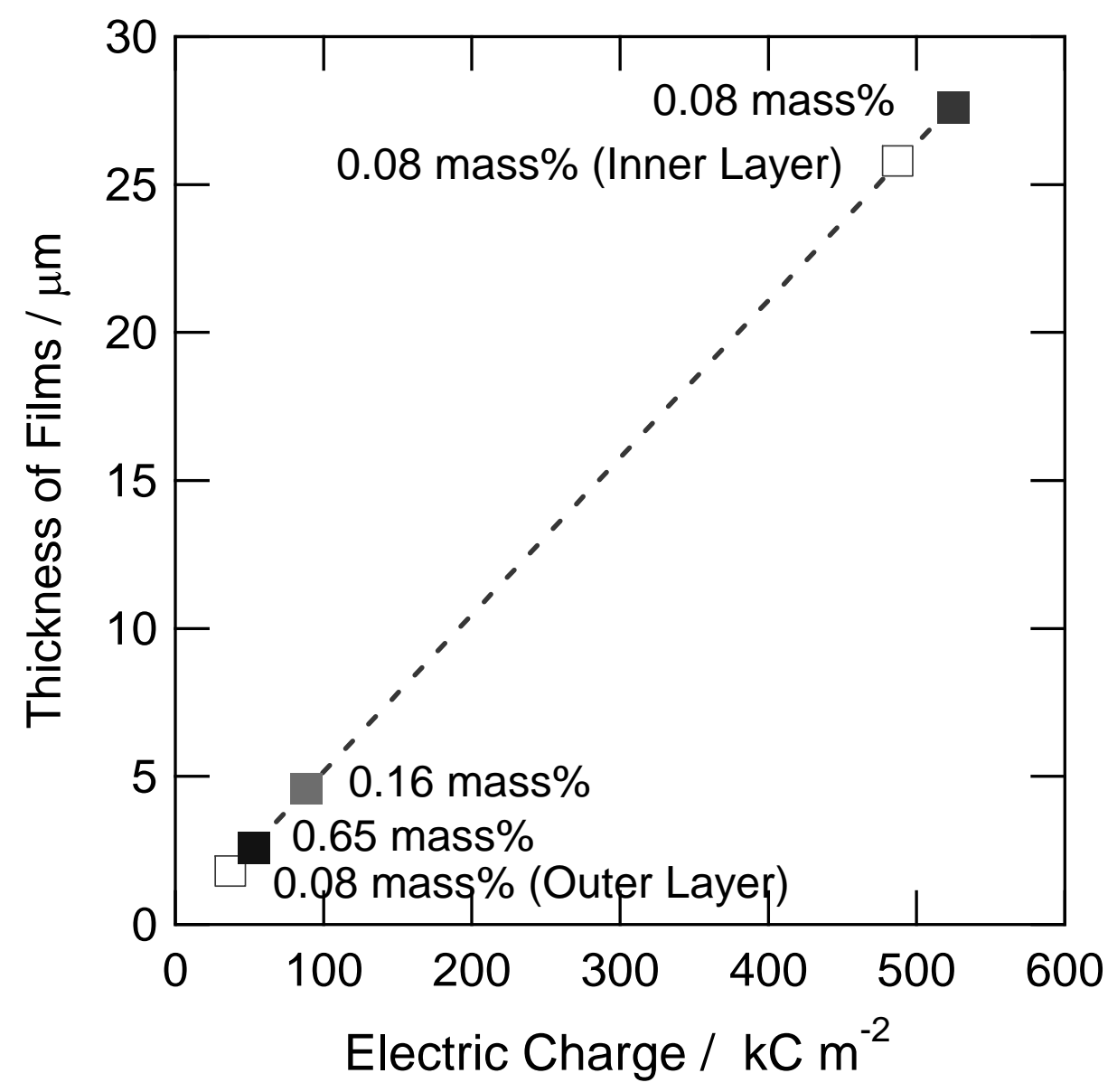

Fig. 4 Correlation between the thickness of the anodic oxide films formed and the electric charge passed during anodizing at $250 \mathrm{~A} \mathrm{~m}^{-2}$ to $10 \mathrm{~V}$ with current decay for $3.6 \mathrm{ks}$ in $0.8 \mathrm{~mol}$ $\mathrm{dm}^{-3} \mathrm{~K}_{2} \mathrm{HPO}_{4}$-glycerol electrolytes with three different water contents at $433 \mathrm{~K}$. The correlation for the anodic film formed during initial constant current anodizing and that during the subsequent constant voltage anodizing in the electrolyte containing 0.08 mass\% water are also plotted. 

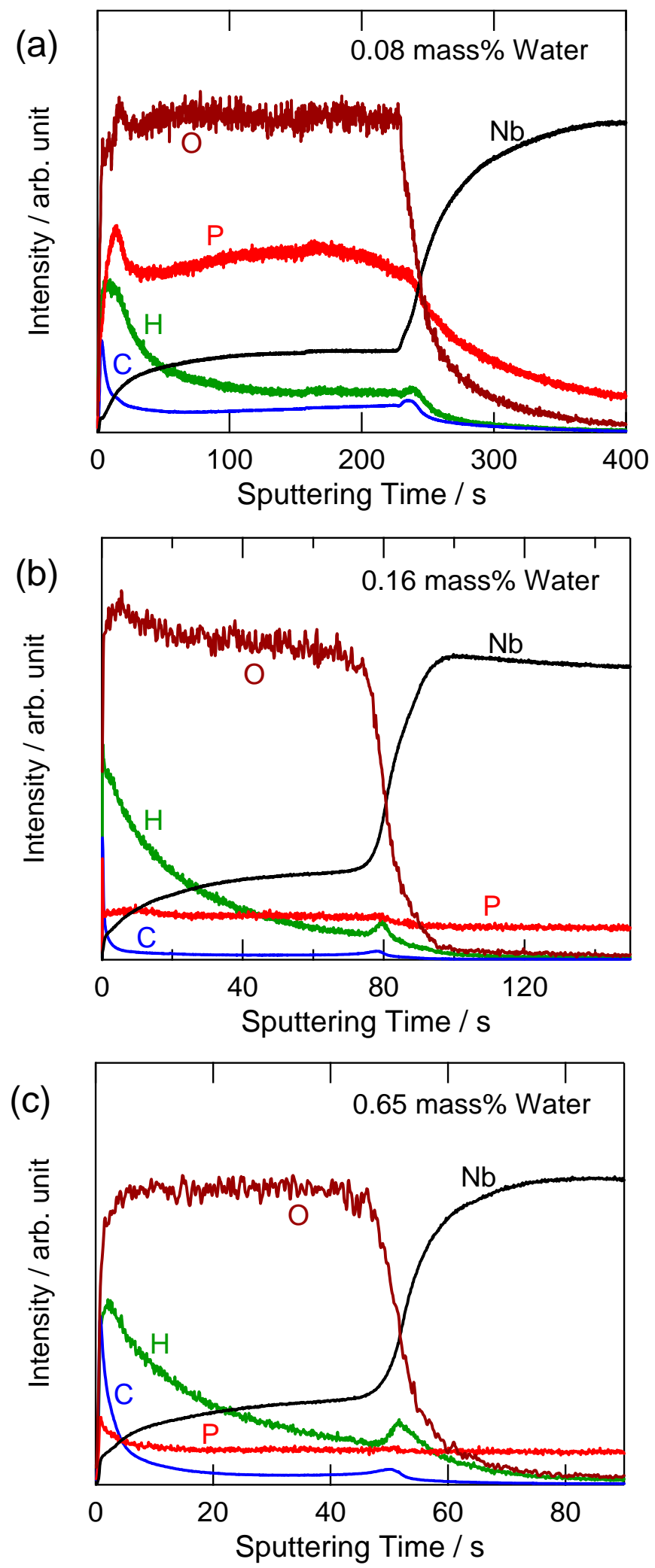

Fig. 5 GDOES elemental depth profiles of niobium specimens anodized at $250 \mathrm{~A} \mathrm{~m}^{-2}$ to $10 \mathrm{~V}$ with current decay for $3.6 \mathrm{ks}$ in $0.8 \mathrm{~mol} \mathrm{dm}^{-3} \mathrm{~K}_{2} \mathrm{HPO}_{4}$-glycerol electrolytes with (a) 0.08 , (c) 0.16 and (d) 0.65 mass\% water at $433 \mathrm{~K}$. 
(a)

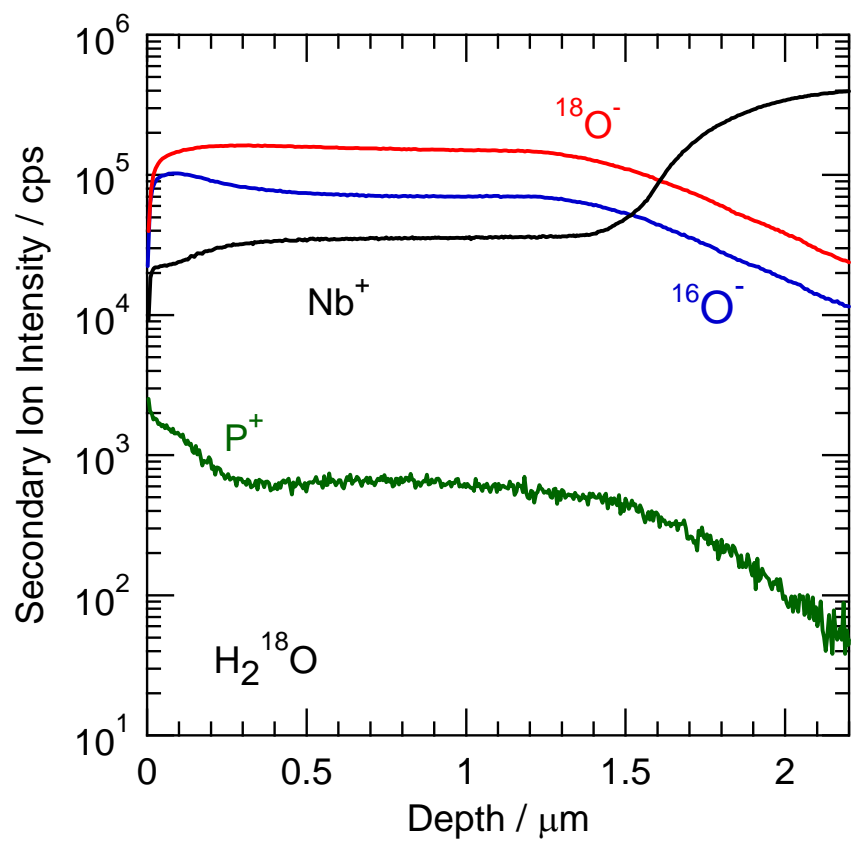

(b)

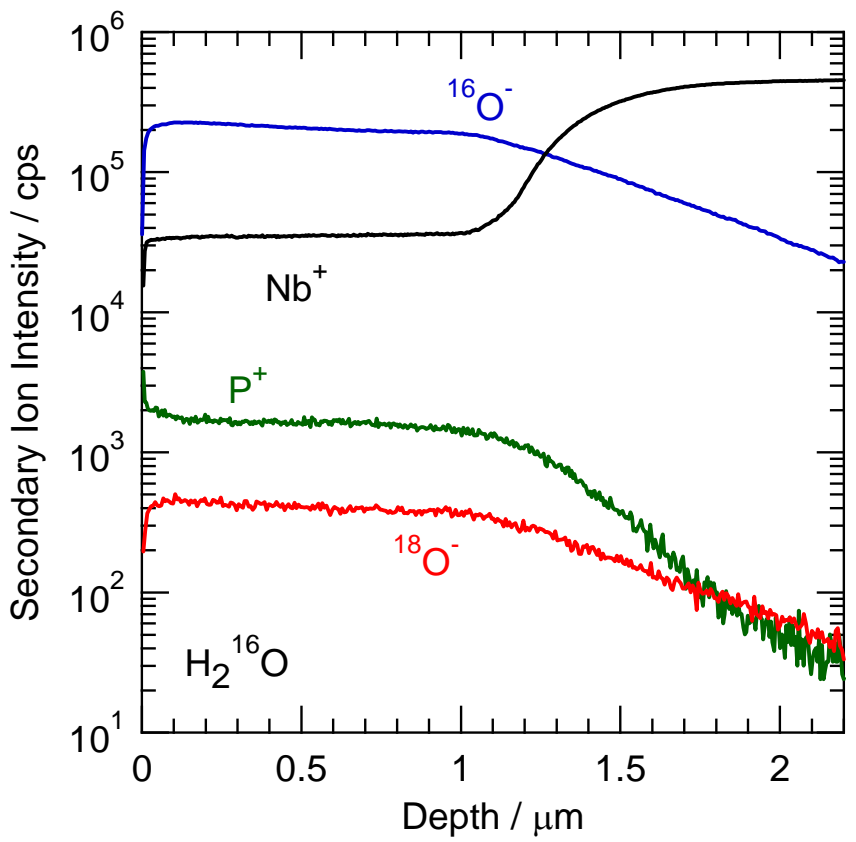

Fig. 6 SIMS depth profiles of the niobium specimens anodized at $250 \mathrm{~A} \mathrm{~m}^{-2}$ to $10 \mathrm{~V}$ with current decay for $600 \mathrm{~s}$ in $0.8 \mathrm{~mol} \mathrm{dm}{ }^{-3} \mathrm{~K}_{2} \mathrm{HPO}_{4}$-glycerol electrolytes (a) with $\mathrm{H}_{2}{ }^{18} \mathrm{O}$ enrichment and (b) without $\mathrm{H}_{2}{ }^{18} \mathrm{O}$ enrichment at $433 \mathrm{~K}$. 
Table 1 The final current density during anodizing of niobium at $10 \mathrm{~V}$ in $0.8 \mathrm{~mol} \mathrm{dm}^{-3}$ $\mathrm{K}_{2} \mathrm{HPO}_{4}$-glycerol electrolytes with different water concentrations for $3.6 \mathrm{ks}$ and the voltage surge during re-anodizing at $5 \mathrm{~A} \mathrm{~m}^{-2}$ in $0.5 \mathrm{~mol} \mathrm{dm}^{-3} \mathrm{H}_{3} \mathrm{BO}_{3}-0.05 \mathrm{~mol} \mathrm{dm}^{-3} \mathrm{Na}_{2} \mathrm{~B}_{4} \mathrm{O}_{7}$ aqueous solution at $293 \mathrm{~K}$.

\begin{tabular}{ccc}
\hline Water content $($ mass\%) & Voltage surge $(\mathrm{V})$ & Final current density $\left(\mathrm{A} \mathrm{m}^{-2}\right)$ \\
\hline 0.08 & 8.1 & 125 \\
0.16 & 13.6 & 18 \\
0.65 & 13.8 & 18 \\
\hline
\end{tabular}

